\title{
Applying Native e-Tourism to Support the Development of Sustainable Tourism
}

\author{
Malgorzata Luc ${ }^{1 *}$, Magdalena Tejwan-Bopp ${ }^{2}$, Clemens Bopp ${ }^{3}$ and Jacek Boguslaw Szmanda ${ }^{4}$ \\ 1 Jagiellonian University, Geography and Spatial Management, Gronostajowa 7, Krakow, Poland \\ ${ }^{2}$ Magdalena Tejwan-Bopp MSc, ETNOS - E-Touristik Nativ Open Service, Poland \\ ${ }^{3}$ Clemens Bopp MSc, eng., ETNOS - E-Touristik Nativ Open Service, Poland \\ ${ }^{4}$ Jacek Boguslaw Szmanda phd hab, Pedagogical University in Cracow, Poland
}

\begin{abstract}
Sustainability is a commonly desirable concept also in individual, non institutionalised tourism, since its main objective is progress, and sustainability provides an opportunity for correct and reasonable management. Our proposition of creating native e-tourism fits into this system perfectly as it arose from the combination of native, ethnic tourism and electronic tools (e-tourism) and is very close to slow and responsible tourism. Native e-tourism promotes an approach of giving a chance for local communities to become a service provider without any intermediate party in a well-known environment they have a strong connection with. This paper, by proposing an idea of a native e-tourism, is a contribution to a theoretical discussion on a tourism typology and the definition of sustainable tourism. The authors try to find a solution to a problem of integrity of sustainability, the customer's interests, efficiency requirements and local society's vision of development; and to prove that a single, native supplier with the use of electronic technology may create a system of private enterprise and remain sustainable in their operations. The publication is a case study, an incorporation of theory into applied work and takes part in a discussion on the contemporary and future trends in tourism.
\end{abstract}

Keywords: Sustainable tourism; Native tourism; e-Tourism management; Tourism typology; Internet portal; Local society enterprise

\section{Introduction}

At its core, travelling is a social experience throughout a trip's cycle. Travelers wish to reunite with their friends, family or meet local people, and they gather information to make their trips as personal and provincial as possible, no matter whether they are still in the planning process, or whether they are already out. It is a well-known issue and not a new concept of tourism. However, relatively easy access to most of the places around the world, and the development of the economy result in the expansion of tourism within society, influenced by varied private and professional motivations. Hence, consequently over the past decade, new forms of tourism have developed and information technologies became practically inseparable from them. In this publication, as a background for our discussion, we are going to use the basic tourism typology according to the UNWTO (United Nations World Tourism Organization Network) with some modifications (Figure 1). However, we shall focus on individual tourism (families on their own), the form opposed by organized, mass tourism (by travel agency), which is the result of the globalization tendency.

Within individual tourism, there are several fractions such as qualified (also called adventure) tourism in specialized forms differentiated according to e.g. place, sport discipline, event, activity, ideology etc. Individual qualified tourism is associated with personal qualifications which a tourist must have. After all, covering a distance in space requires physical exercise and a better arrangement (than a traditional tourist), organizational skills and competences in using specialist equipment, having a certain store of general knowledge and, above all, self-reliance. Such a tourist belonging to the category of non-institutionalized tourism, according to Cohen's typology (1972), was named an explorer or a drifter, depending on the degree of connection to the tourist establishment (hotels, tour coaches, etc.) and the extent of blending in with the widely understood local culture, and an attempt to live the way the locals do. Above all it should be noted that non-institutionalized tourism has a lesser impact on environment or culture of the destination countries than institutionalized tourism. Its enthusiasts obey pro-ecological norms of behaviour, respect local culture, merge activities with comprehensive acquaintance of the visited region.

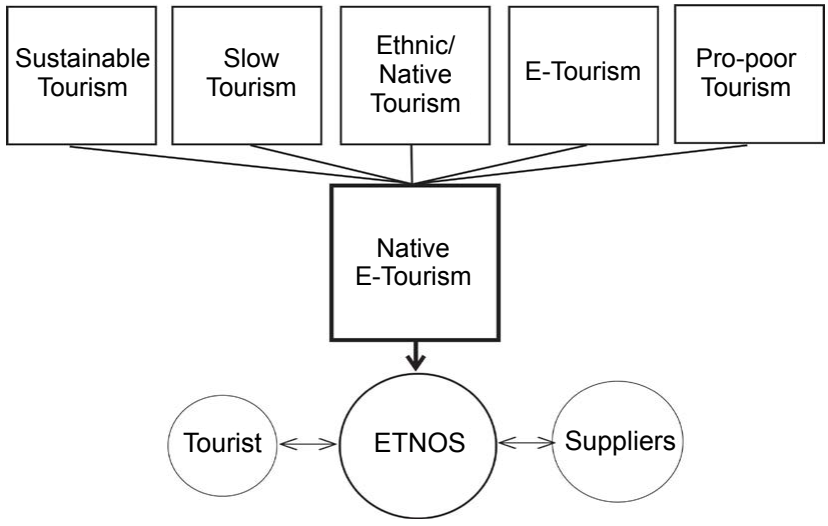

Figure 1: The conceptual model of the ETNOS idea.

*Corresponding author: Malgorzata Luc, Jagiellonian University, Geography and Spatial Management, Gronostajowa 7, Krakow, Poland, Tel: +48 1242210 33; E-mail:mluc@gis.geo.uj.edu.pl

Received September 06, 2016; Accepted September 23, 2016; Published September 30, 2016

Citation: Luc M, Tejwan-Bopp M, Bopp C, Szmanda JB (2016) Applying Native e-Tourism to Support the Development of Sustainable Tourism. J Tourism Hospit 5: 246. doi: 10.4172/2167-0269.1000246

Copyright: (c) 2016 Luc M, et al. This is an open-access article distributed under the terms of the Creative Commons Attribution License, which permits unrestricted use, distribution, and reproduction in any medium, provided the original author and source are credited. 
The subject of this publication concerns native tourism. It is strongly related to sustainable tourism, ecotourism [1-3], as well as to non-institutionalized, adventure tourism. This concept is also known as responsible tourism where needs of local communities, business and the tourist are equally important [4]. The paper focuses mainly on an aspect of sustainability as an important area of promise and of concern but from the perspective of client-customer (supplier) relation. However, what should be done to integrate sustainability, the customer's interests and efficiency requirements in order to use the full potential of tourism? In response to this question we propose to take a new approach in incorporating sustainability ideology into local society interests anchored in tourism, and as a result to combine the idea of native tourism and e-tourism in a new pattern which, as a natural consequence, we called Native e-Tourism. Therefore, the purpose of the presented study is to define this new typological class and to prove the appropriateness of separation of a native e-tourism from non-institutionalized tourism of drifters and explorers who also represent qualified tourism. Moreover, the paper explains the necessity and presents arguments for creating this new structure, as a response to developing globalization in tourism. The main drivers of sustainability in native e-tourism are also highlighted. The publication is a case study and promotes native e-tourism by the use of an already successfully working IT tool in a form of a web portal.

The portal combines the assumptions of native tourism, and has become a tool for tourists' communication with the local population providing tourist services specific to the region. A discussion of its assumptions, ways of functioning, and characteristics of the target groups on both the provider's and the recipient's sides contributes into an application purpose of this study.

Generally, the concept of native tourism is not new but the paper presents a case study disseminated into practice. In that way we incorporate theory into applied work and take part in a discussion on the contemporary and future trends in tourism. The paper concludes with a statement that a single, native supplier with the use of electronic technology may create a system of private enterprise and maintain sustainable in his operations.

\section{Idea of a Native e-Tourism}

After Williams and Stewart [5], and McIntosh and Goeldner [6], we connect native tourism with learning knowledge and gaining experience through observation and participation in the life of indigenous people. Similar assumptions function in ethnic tourism, understood as a combination of nature and cultural tourism [7]. However in native tourism the focus put on ethnic minorities is replaced with a focus on local communities [8-10]. According to Smith [11], native tourism is determined by the so-called " $4 \mathrm{H}$ 's of tourism", which comprise (1) habitat, (2) heritage, (3) history, (4) handicraft. Currently, it is practised by a growing group of tourists showing interest in travelling to unusual places, or using non-standard forms of travelling both in the category of places, transportation and accommodation, as well as regards all the activities conducted during a trip. Exploring new places is carried out with the involvement of local people. On the other hand, native society engages in public-private partnerships, and involves in tourism-related programs to contribute towards ecotourism objectives in places valuable for them [12].

In the information society a large part of the value added comprises of information, and the development of supply and demand depends on the simplicity and speed of its transfer. Functioning in such a society is a challenge for all of us. This trend is also reflected in tourism in the form of e-tourism, a tool for tourist services, and a reflection of tourist processes in a digital format consisting mainly in the flow of information [13]. The concept of e-tourism is therefore based on the combination of geographic information systems with tourism as an idea on the border between social and economic development.

The basis for the idea of introducing the notion of native e-tourism into general use through a web portal is a multifaceted one. First of all, working with local communities, especially in developing and emerging countries, adds authenticity to tourism products. It drives innovation and variety, and sets products apart from the mainstream, reduces risks and costs. Local communities benefit from better incomes, improved skills and opportunities, and the conversion of natural and cultural resources. Internet portal acts here as a go-between with regard to the direct contact between a service provider (in the case of native e-tourism, the local population) and a service user (tourist). Unlimited opportunities to exchange information on the services offered, and also its dissemination to unlimited groups of individual tourists, especially those interested in specialist offers, are formed in this way. Native e-tourism is a reflection of Wheller's views, who believes that tourism should be developed by the local community in a slow and controlled way, while maintaining a small scale of this phenomenon.

Usage of a web portal means finding out how you, as a tourist as well as a supplier (Figure 1), can work with local communities, learn from inspiring examples, and meet partners. In addition, the implementation of the idea of native e-tourism requires a new way of investing in and promoting the region in order to attract visitors, and keep them there for longer. Significant opportunities are provided by combining different ways of practising tourism. In this way, a system of interrelationships that take into account the new socio-economic conditions, the nature of demand for services, and the type of trade in goods and services, is established. Native e-tourism fits perfectly into the development of such systems of local IT connections that enable dissemination of information about tourist offers provided by indigenous people. New social and economic opportunities are thus created, and by promoting the ecological approach and caring for one's own environment these people are creating real chances of protecting their environment.

\section{Native e-Tourism as a Basis for Sustainable Tourism}

Creating a counterweight to mass tourism by native e-tourism fits very well in the ideology of sustainable tourism. According to UNWTO, sustainable tourism is one "which meets the needs of present tourists and host regions while protecting and enhancing opportunity for the future." [14]. Therefore, social, economic and environmental integration especially in developing countries, or in underdeveloped areas with significant tourism potential, but where globalism (which constitutes the opposite of sustainability) is not yet widespread at least in tourism, is striven for. In this sense, native e-tourism is the antithesis of globalization; it is conscious, individual travelling using direct contacts with people without using the services of tourist agencies. This rejection of mass tourism means that travellers are involved in getting to know the country of destination through direct relationships thus, in a sense, taking over responsibility for the sustainable development of the world.

The native e-tourism idea is also consistent with the United Nations 2030 agenda for global action [15], particularly with Goal 8 and 12 (out of 17). These goals read as follows: Goal 8. Promote sustained, inclusive and sustainable economic growth, full and productive employment, and decent work for all; 8.9 by 2030 , devise and implement policies 
that promote sustainable tourism that creates jobs and promotes local culture and products; and Goal 12. Ensure sustainable consumption and production patterns; 12.b Develop and implement tools that monitor sustainable development impacts for sustainable tourism that creates jobs and promotes local culture and products [15].

The concept of sustainable tourism has its roots in Hettner's holistic ideology of responsible tourism. Its pillars create such ideas as minimizing interference with the natural environment, respecting cultural diversity, maximizing the participation of local people in providing tourist services, and increasing the satisfaction of tourists [4,16-20]. However, in the later period, responsible tourism was partially replaced by other types of tourism, as a result of which the concept of native tourism within the meaning of aboriginal tourism was not widely used, but remained in selected countries including Canada, Australia, the USA (Alaska).

Since native e-tourism is to assist directly local vendors in the countries concerned, it is close to the concept of fair trade [21]. The theory of fair trade involves providing aid to small, local producers (service providers in the case of native e-tourism). At the same time, it is one of the trends of social economics, whose guiding principle is the recognition of man as being more important than profit. This goal is implemented in tourism through the premises of pro-poor tourism [22], which strategy provides equality in distributing tourism benefits [23]. According to this ideology, but also to sustainable tourism, it is possible by ensuring equal opportunities of access to the markets of richer countries for producers marginalized in the globalization process. Such an approach challenges the trade practices that keep people in poverty, which may also apply to a narrow branch of trade, i.e. tourism. Therefore, translating the language of fair trade into the ideology of sustainable tourism, we can say that its goal is to build lasting relationships between service providers and consumers, accompanied by respect and care for people and the environment [24]. This means an increase in the awareness of the situation of producers and traders in poor countries; protection of the rights of women, children and indigenous people; building respect for the values represented by the local environment which the population living there depends upon, by creating for these producers resources and opportunities to improve their living and working conditions (including the protection of their environment).

The term native e-tourism as a form of travelling is also convergent with the notion of slow travel, slow tourism. Slow travel, as Dickinson and Lumsdom [25] write, is associated with hiking, biking, and water tourism (e.g. ferries, cruising, canoes, kayaks, yachts), but also with the use of rail and bus transport. Slow tourism is more a philosophy of travelling than its form; it is a state of mind; it is a social movement promoting spending holidays slowly in accordance with the principle that it is better to do things more accurately than to do more of them. The slow travel manifesto for tourists coincides at several points with the idea of native tourism, for example, Do what the locals do, not only what the guidebooks say, or Engage with communities at the right level. Choose accommodation and eating options that are appropriate to the area where you are travelling, and ultimately think what you can give back to the communities you visit. Such an approach will also strengthen the integration of communities in countries with more difficult economic conditions, and result in a better understanding of economic, social and environmental problems of these areas by the rest of society in the world.

Through native e-tourism we combined sustainable, slow, e-tourism, pro-poor, native and ethnic tourism (Figure 1). This idea promotes individual, qualified exploration of the lifestyle of indigenous people, practising slow tourism based on direct contact between the service provider and the user. Chances for the development of local small businesses increase in parallel with the local society's involvement in using their environmental and cultural potential (Figure 1) [26]

\section{The ETNOS Portal and its Role in Promoting Native e-Tourism}

According to Beeton [27] initiated internet tools to stimulate e-tourism activities allow the spreading of the concept of communitybased tourism, which aims to develop the entrepreneurship of local communities. The core of e-tourism is made up of tools from the group of broadly defined information technology. Therefore, to propagate the idea of native e-tourism, we designed a specialist web portal, which has just starting to operate (www.etnos-global.com). It was created to introduce systemic solutions in the tourism industry, which allow communication between suppliers of tourist services with customers seeking such services. This portal is a result of activities under the project we have called Native E-Tourism Open Services (ETNOS) meaning native e-tourism within open ('free') services provided by local residents for the needs of individual tourism. The etymology of the word ethnos is derived from the Greek term for people, tribe or nation. Currently, Ethnos is a group of people with a sense of common origin, common culture and group ties which perfectly well fits in philosophy of native e-tourism.

The concept of the ETNOS portal has already been presented in a Polish publication [28] but it is worth repeating that it was based on developing a database of suppliers of tourist services from around the world and making contact details available to any person/customer through it. In addition, a client receives a detailed description of the service offered and the rating of given service providers issued by other users. All economic entities and various persons providing certain services related to tourism worldwide should be considered as tourist service providers. In order to enable the greatest number of interested people to use the portal, the information posted on it is provided in several languages. This portal is also a social networking site linked to Facebook, Twitter, Google+ and Pinterest, which allows the extension of the group of potential customers.

The portal provides, free of charge, data of tourist services suppliers from around the world. Therefore, on the one hand, the portal was prepared for providers of tourist services and, on the other hand, for customers seeking local offers. Offerors may be small, local tourist companies, private individuals, as well as "non-profit" organizations. Joining the portal, a service provider may post their proposition under various tourist categories. These categories relate to native e-tourism ideology and include the following tourist activities: (1) active leisure, (2) guiding and piloting services, (3) accommodation, (4) educational and voluntary services, (5) work \& travel, (6) gastronomy, (7) extreme sports, (8) transport services including car rental, (9) equipment rentals.

Since posting reports from trips on the internet is becoming increasingly common, it is also possible for travellers to publish accounts from their trips in the form of a blog. Travel reports can be placed on the main page of the website as possible proposals of itineraries for those who do not have any more specific plans as yet. In addition, attractions and offers of services available in little-known tourist areas (the so-called bio- and geo-diversity in tourism) are published by the local population. 
The ETNOS portal is not the only tourism portal functioning on the internet. Similar, but significantly reduced opportunities of establishing contact between service providers and tourists are available on other web portals. Examples include the www.airbnb.com portal, which allows accommodation to be found directly with local private providers in certain tourist areas, or the www.lookals.com portal through which you can contact the offerors of local tourist services only in Italy. Other similar portals include $[29,30]$.

According to native e-tourism concept internet portal that promotes sustainable tourism should apply the broad principles of netiquette. ETNOS is a portal designed for people open to the world and foreign cultures; therefore, any racist comments, or ones discriminating with regard to the society in a given country or region of the world are unacceptable. Comments on controversial political issues are also out of the question. Ratings provided on the site must be truthful and presented in a way that does not violate ethical principles. ETNOS is a portal for all tourist entities, which should be equal regardless of their size, financial performance, and range of activities. In its assumptions, the portal aims to gather as many areas of Internet tourist activities as possible, in order to best help individual tourists in their preparation of trips (according to their own preferences) to the destination of their choice, and to satisfy their individual needs.

Created web portal promotes the idea of sustainable tourism as a way of environmental management in accordance with the principles of ecology and sustainability, the idea of native e-tourism practising slow tourism based on direct contact between the service provider and the user.

\section{Discussion and Conclusion}

Various solutions to create systems functioning in tourism on the principles of sustainability of environmental, social and economic factors are being looked for in the world. The idea of sustainable tourism based on using the potential of the local community and the qualities of the region's environment, without detriment to each of these factors, is associated with a rather niche approach to travelling. It was in the course of this search that the ETNOS project emerged combining in itself the idea of sustainable, slow, and native tourism. With the help of the internet portal, we want to support local tourism initiatives and meet the needs of specific groups of tourists interested in individual experiencing the qualities of indigenous nature and the culture of tourist areas. Continuous development and the increasing prevalence of the use of information technology continue to expand the possibilities of using them in terms of individual, qualified tourism, particularly native e-tourism. The authors of the article count on the interest in the ETNOS portal on the part of both service providers and tourists, in order to help both groups implement their plans, and satisfy their needs.

\section{References}

1. Ross S, Wall G (1999) Ecotourism: Towards congruence between theory and practice. Tourism Management 20: 123-132.

2. Björk P (2000) Ecotourism from a Conceptual Perspective, an Extended Definition of a Unique Tourism Form. International Journal of Tourism Research 2: 189-202.

3. Weaver DB, Lawton LJ (2007) Twenty years on: The state of contemporary ecotourism research. Tourism Management 28: 1168-1179.

4. MacLeod, Nicola (2016) Self-guided trails - a route to more responsible tourism? Tourism Recreation Research 41: 2.

5. Williams PW, Steward JK (1997) Canadian aboriginal tourism development: Assessing latent demand for France. The Journal of Tourism Studies 8: 25-41.
6. Mclntosh RW, Goeldner CR (1990) Tourism principles, practices and philosophies. (6thedn), John Wiley, New York.

7. King B (1994) What is ethnic tourism? An Australian perspective. Tourism Management 15: 173-176.

8. Yang L, Wall G (2009) Ethnic tourism: A framework and an application. Tourism Management 30: 559-570.

9. Yang L, Wall G (2014) Planning for Ethnic Tourism. Routledge, London and New York.

10. Yang $L$ (2010) Ethnic tourism and cultural representation. Annals of Tourism Research 32: 561-585.

11. Smith VL (1996) Indigenous Tourism: The Four H's. In: Butler RW, Hinch T (eds.) Tourism and Indigenous Peoples. London: International Thomson Business Press.

12. Bhalla $P$, Coghlan A, Bhattacharya $P$ (2016) Homestays' contribution to community-based ecotourism in the Himalayan region of India. Tourism Recreation Research 41: 213-228.

13. Buhalis D (2003) e-Tourism: information technology for strategic tourism management. Harlow: Prentice Hall.

14. World Tourism Organization (1993) Sustainable Tourism Development: Guide for Local Planners. Madrid: WTO.

15. UN (2015) Transforming our world: the 2030 agenda for global action. Fina draft of the outcome document for the UN Summit to adopt the Post-2015 Development Agenda.

16. Hunter C, Green H (1995) Tourism and the environment a sustainable relationships. Routledge, London.

17. Hunter C (1997) Sustainable tourism as an adaptive paradigm. Annals of Tourism Research 24: 850-867.

18. Stabler MJ (1997) Tourism and sustainability: principles to practice. CAB International, Wallingford.

19. Butler RW (1999) Sustainable Tourism: a state of the art review. Tourism Geographies 1: 7-25.

20. Sharplay R (2002) Tourism and sustainable development, exploring the theoretical divide. Journal of Sustainable Tourism 8: 1-19.

21. Nelson V, Barry P (2009) The Last Ten Years: A Comprehensive Review of the Literature on the Impact of Fairtrade. Natural Resources Institute, Greenwich.

22. Spenceley A, Meyer D (2012) Tourism and poverty reduction, theory and practice in less economically develop countries. Journal of Sustainable Tourism 20: 297-317.

23. Sharpley R, Telfer DJ (2015) Tourism and development, concepts and issues. Bristol: Channel View Publications.

24. Cleverdon R, Kalisch A (2000) Fair Trade In Tourism. International Journal of Tourism Research 2: 171-187.

25. Dickinson J, Lumsdom L (2010) Slow travel and Tourism. Eathscan, London.

26. Nicky Gardner (2008) A manifesto for slow travel. hidden europe 25.

27. Beeton S (2006) Community development through tourism. Cilligwood Landlinks Press.

28. Luc M (2015) Approaches in Sustainable 'Landscaping' - A Geographical Perspective. In: Luc M, Somorowska U, Szmańda JB (eds.) Landscape Analysis and Planning: Geographical Perspectives. Switzerland: Springer Geography, pp. 201-216.

29. Cohen E (1972) Towards a sociology of international tourism. Social Research 39: $164-182$.

30. Luc M, Tejwan-Bopp M, Bopp C, Szmańda JB (2016) E-tourism native development opportunity przedsiębiorczościwśród local communities [Native e-tourism as an opportunity for development of entrepreneurship in local communities].Przedsiębiorczość-Edukacja 12: 233-243. 